\title{
PUSAT PENANGANAN OBESITAS BERBASIS KARAKTER INDIVIDUAL
}

\author{
Chessa Chrysantha ${ }^{1)}$, Alvin Hadiwono ${ }^{21}$ \\ 1) Program Studi S1 Arsitektur, Fakultas Teknik, Universitas Tarumanagara, chessachrysanthaa@gmail.com \\ 2) Program Studi S1 Arsitektur, Fakultas Teknik, Universitas Tarumanagara, alvinhadiwono@ymail.com
}

\begin{abstract}
Abstrak
Obesitas merupakan salah satu problem pandemik dalam dunia yang pengobatannya masih dipandang sebelah mata. Dengan jumlah penderita yang terus bertambah, dan jaman yang semakin berkembang, untuk itu diperlukan sebuah fasilitas untuk menangani masalah obesitas seiring dengan perilaku dan sikap generasi sekarang. Menurut American Psychological Association, sikap dan karakter seseorang dapat mempengaruhi berat badannya. Saat ini, penanganan obesitas hanya terpaku pada penanganan fisik saja. Hal itu menyebabkan pengobatan yang dilakukan pasien akan menjadi tidak efektif untuk penurunan berat badan jangka panjang. Karena itu, dibutuhkan sebuah fasilitas yang memfokuskan kepada pengobatan fisik dan psikologis pasien, sehingga hasil pengobatan dapat menjadi lebih maksimal dan berjangka panjang. Fasilitas penanganan obesitas yang dimaksud berupa perancangan sebuah fasilitas yang memprioritaskan hanya kepada para penderita obesitas dan berfokus kepada psikologis pasien tanpa mengesampingkan kondisi fisik pasien. Rancangan fasilitas ini menggunakan metode pengelompokkan kepribadian manusia menurut Lewis Goldberg, kemudian masing-masing kepribadian yang cocok dengan penyebab meningkatnya jaringan adiposa tubuh akan diterjemahkan menjadi ruang-ruang pengobatan dan kebutuhan pasien. Ruang-ruang publik juga ditambahkan dalam proses desain dengan harapan agar para penderita dan publik dapat berinteraksi sekaligus sebagai salah satu sarana terapi sosial. Dengan adanya pusat pengobatan yang berfokus kepada obesitas, diharapkan tingkat kewaspadaan masyarakat meningkat terhadap bahaya obesitas dan para penderita obesitas tidak merasa tersingkirkan.
\end{abstract}

Kata kunci: fisik; obesitas; pengobatan; perancangan; psikologis

\begin{abstract}
Obesity is one of the world's pandemic problems for which it's cure is still underestimated. With the increasing amount of people with obesity, and the evolving of time, a facility to handle obesity problems according to the behaviour and attitude of present generations is needed. According to the American Psychological Association, a person's behaviour and character could have an influence on their weight. Nowadays, treatment of obesity is mostly about physical treatment only. It causes a patient's treatment to not be effective for long-term weight loss. Because of that, a facility that focuses on both physical and psychological treatment for patients is needed, so that the result can be maximal and lasts longer. The intended facility design prioritize patients psychological condition without putting physical condition aside. The design use Lewis Goldberg's Five Factor Model mostly for the main programs, especially the personalities that has been verified as a cause of obesity. Each personalities would be translated as treatment rooms. Public facilities was also included in the design process for patient's interaction and social therapy. Other main goal of the project is to raising people's concern about obesity and the dangerous effects of it.
\end{abstract}

Keywords: design; obesity; physical; psychological; treatment

\section{PENDAHULUAN}

Seiring dengan semakin berkembangnya teknologi dan zaman, semakin bertambah pula restoran-restoran fast food yang menyebar di seluruh dunia Padahal, fast food merupakan makanan yang tidak sehat karena mengandung minyak, tinggi gula, terkontaminasi peptisida dan tinggi kalori sebagai akibat dari banyaknya bahan kimia di dalamnya. Jika dibiarkan terusterusan, banyaknya konsumsi makanan cepat saji diiringi dengan pola hidup yang tidak sehat 
dapat berdampak bagi tubuh dengan berbahaya. Contohnya adalah penyakit gangguan penyerapan gizi dan obesitas yang dapat merujuk ke berbagai penyakit berbahaya lainnya seperti jantung, stroke, darah tinggi, diabetes dan lainnya.

Obesitas merupakan sebuah masalah besar di berbagai belahan dunia. Saat ini, meunrut World Health Organization (WHO), 2,2 miliar penduduk dunia telah mengalami kasus obesitas dengan negara yang memiliki jumlah penduduk obesitas tertinggi dipegang oleh Arab Saudi dan Kuwait. Indonesia sendiri memegang urutan ke-7 dari negara dengan jumlah penduduk obesitas terbanyak di dunia. Hasil dari Riset Kesehatan Dasar (Riskesdas) tahun 2018 mengatakan bahwa tingkat prevalensi obesitas pada orang dewasa meningkat menjadi $21.8 \%$ dibanding tahun lalu. Saat ini telah ada 40 juta penduduk Indonesia yang telah mengalami obesitas. Hal ini berarti 1 dari 4 orang Indonesia berpotensi mengalami obesitas.

\section{Persentase obesitas 100 negara dengan populasi penduduk terbanyak}

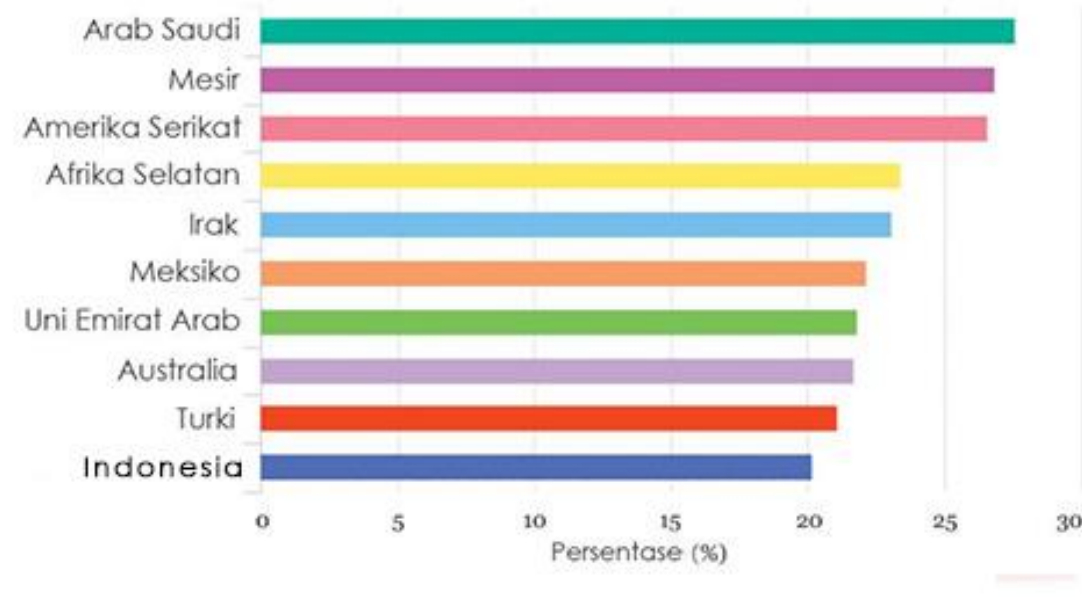

Daftar negara dengan tingkat obesitas paling tinggi di dunia. (GABY/ NETZ)

Gambar 1. Persentase Penduduk Obesitas Tertinggi di Dunia Sumber: netz.id/news

Generasi milenial berperan penting tidak hanya sebagai salah satu penyebab bertambahnya jumlah penderita obesitas, tetapi juga sebagai salah satu penemu solusi dari isu yang semakin marak sehingga untuk kedepannya diharapkan isu obesitas ini dapat diatasi dengan cara milenial. Saat ini, pengobatan obesitas lebih berfokus kepada pengobatan fisik saja. Padahal, setelah diteliti, kondisi psikologis dan emosional seseorang juga berperan dalam menentukan berat badan orang tersebut. Hal itu seringkali terlupakan, sehingga pengobatan obesitas menjadi tidak efektif dalam menurunkan berat badan jangka panjang. Sehingga pada masa kini, pengobatan obesitas yang ada dapat dikatakan belum efektif.

Sisi pengobatan yang tidak efektif tersebut tentu harus diperbaiki untuk menekan pertumbuhan jumlah pasien obesitas. Salah satunya adalah dengan cara menghadirkan sebuah fasilitas yang berfokus kepada pengobatan obesitas yang sesuai dengan kebutuhan para penderitanya, agar pengobatan dapat menjadi lebih terfokus dan efektif.

\section{KAJIAN LITERATUR}

\section{Hubungan Kepribadian Psikologis dengan Berat Badan Manusia}

Obesitas didefinisikan sebagai kandungan lemak yang berlebihan di jaringan adiposa. Dimana secara fisiologis didefinisikan sebagai keadaan dengan akumulasi lemak tidak normal di jaringan adiposa hingga mengganggu kesehatan (Sugondo, 2009). Penyakit ini dapat terjadi jika adanya peningkatan pemasukan energi secara berlebihan diiringi dengan penurunan pengeluaran 
energi. Obesitas sendiri dapat disebabkan oleh banyak faktor, seperti genetik, lingkungan, psikis, kesehatan, obat, kurangnya aktivitas fisik, dan sebagainya.

American Psychological Association (APA) bagian Psikologi Kepribadian dan Sosial menemukan bahwa perilaku impulsif adalah prediktor terkuat dalam menentukan siapa yang kelebihan berat badan. National Institute of Ageing menganalisa data dari studi terhadap 2000 orang mengenai kepribadian-kepribadian psikologis apa saja yang berhubungan dengan berat badan dan BMI. Studi APA mengatakan bahwa orang yang impulsif, mudah depresi, dan kurang disiplin merupakan orang yang cenderung lebih rentan terhadap pola hidup yang tidak sehat dan berujung kepada masalah obesitas, sedangkan orang yang memiliki neurotisisme (ketidakseimbangan mental sehingga menyebabkan stress) yang tinggi cenderung lebih mudah kehilangan berat badan mereka.

Selain itu, terdapat lima kepribadian yang utama dimiliki oleh manusia yaitu keterbukaan, sifat berhati-hati, ekstraversi, mudah menerima dan neurotisisme yang dikemukakan oleh Lewis Goldberg. Lima kepribadian dasar tersebut, memiliki hubungan yang erat dengan kesehatan manusia secara umum (Friedman, 2008) dan berhubungan juga dengan obesitas atau kelebihan berat badan (Brummett, 2006). Dari kelima kepribadian tersebut, orang yang memiliki sifat berhati-hati, disiplin, dan teratur memiliki kandungan adiposa dalam tubuh yang lebih rendah (Brummet, 2006). Sebaliknya, orang yang memiliki ekstraversi yang tinggi lebih cenderung memiliki berat badan yang bertambah (Kakizaki 2008), sedangkan sifat keterbukaan seseorang tidak berhubungan dengan kenaikan berat badan atau BMI (Chapman, 2009; Terracciano, 2009).

\section{Metode Penanganan Obesitas Masa Kini Tidak Efektif untuk Jangka Panjang}

Saat ini, pengobatan yang efektif terhadap obesitas masih terus diperdebatkan. Diketahui bahwa $90 \%$ hingga $95 \%$ pasien yang menjalankan terapi diet akan kembali naik berat badannya dalam beberapa tahun. Berdasarkan data tersebut, maka tentu penanganan obesitas harus lebih diperhatikan dan dikaji kembali.

Diet merupakan bentuk penanganan yang paling universal bagi seluruh penderita obesitas. Tetapi, jika diperhatikan diet sendiri memiliki pengaruh yang besar di dalam berbagai aspek kehidupan pasien. Kesuksesan terapi obesitas dengan diet untuk pasien yang belum pernah melakukan pengobatan sebelumnya dapat dikatakan kecil, dan malah meningkatkan resiko kesehatan lainnya. Diet seringkali mempunyai efek-efek negatif dalam kategori psikologis dan sosial pasien dan jika dilakukan dengan salah, efek ini dapat berujung kepada eating disorder seperti binge eating dan bahkan bulimia nervosa (kondisi dimana seseorang makan terlalu banyak dan tidak dapat dikontrol atau bahkan tidak makan sama sekali). Selain itu, pengobatan dengan diet dan konsultasi juga memiliki harga yang tidak murah. Jika mengalami kegagalan, maka faktor lain yang dapat terkena dampak dari diet yang tidak berhasil adalah psikologis pasien tersebut.

Tidak semua orang dapat diobati dengan cara yang sama. Selain pengobatan fisik seperti mengatur keseimbangan asupan energi dan olahraga yang teratur, kondisi sosial dan emosional pasien yang menderita obesitas juga harus diperhatikan. Seringkali pengobatan dengan metode diet dilakukan dengan menyalahkan keadaan pasien dan pernah adanya diskriminasi dari berbagai kalangan bahkan dari dokter atau tenaga medis sekalipun. Padahal, tujuan dari pengobatan seharusnya tidak berfokus kepada penurunan berat badan saja, namun kondisi pasien tersebut yang harus lebih diperhitungkan.

\section{METODE}

Proyek ini akan memiliki tujuan berupa program yang lebih menitikberatkan kepada kondisi psikologis seorang pasien yang mengalami obesitas tapi tidak mengesampingkan kondisi fisik ideal dan pengobatan secara fisik. Juga untuk menciptakan kondisi lingkungan bagi pasien yang ideal untuk pengobatan. Selain kepada pasien, proyek ini juga memiliki tujuan secara lingkungan yakni untuk meningkatkan kesadaran masyarakat akan bahayanya obesitas sehingga metode yang digunakan untuk penelitian ini adalah dengan metode studi literatur, studi preseden serta 
analisa dan sintesa. Analisa dan sintesa lingkungan berfungsi untuk mengetahui kondisi eksisting pada tapak untuk menentukan usulan bentuk dan saran yang berhubungan dengan lingkungan di sekitarnya. Metode analisa lingkungan digunakan dengan metode survei lapangan dan pengamatan lingkungan, serta pengambilan gambar-gambar pada lokasi terpilih.

Sebelum memulai penelitian, dibentuk kerangka pemikiran isu, problem serta solusi yang ditawarkan agar penelitian dan hasil proyek tidak keluar jalur. Isu penelitian dimulai dari latarbelakang masalah obesitas yang marak di Indonesia serta minimnya fasilitas penanganan obesitas baik yang memadai maupun yang tidak memadai hingga dibutuhkannya fasilitas yang sesuai dengan kriteria generasi milenial.

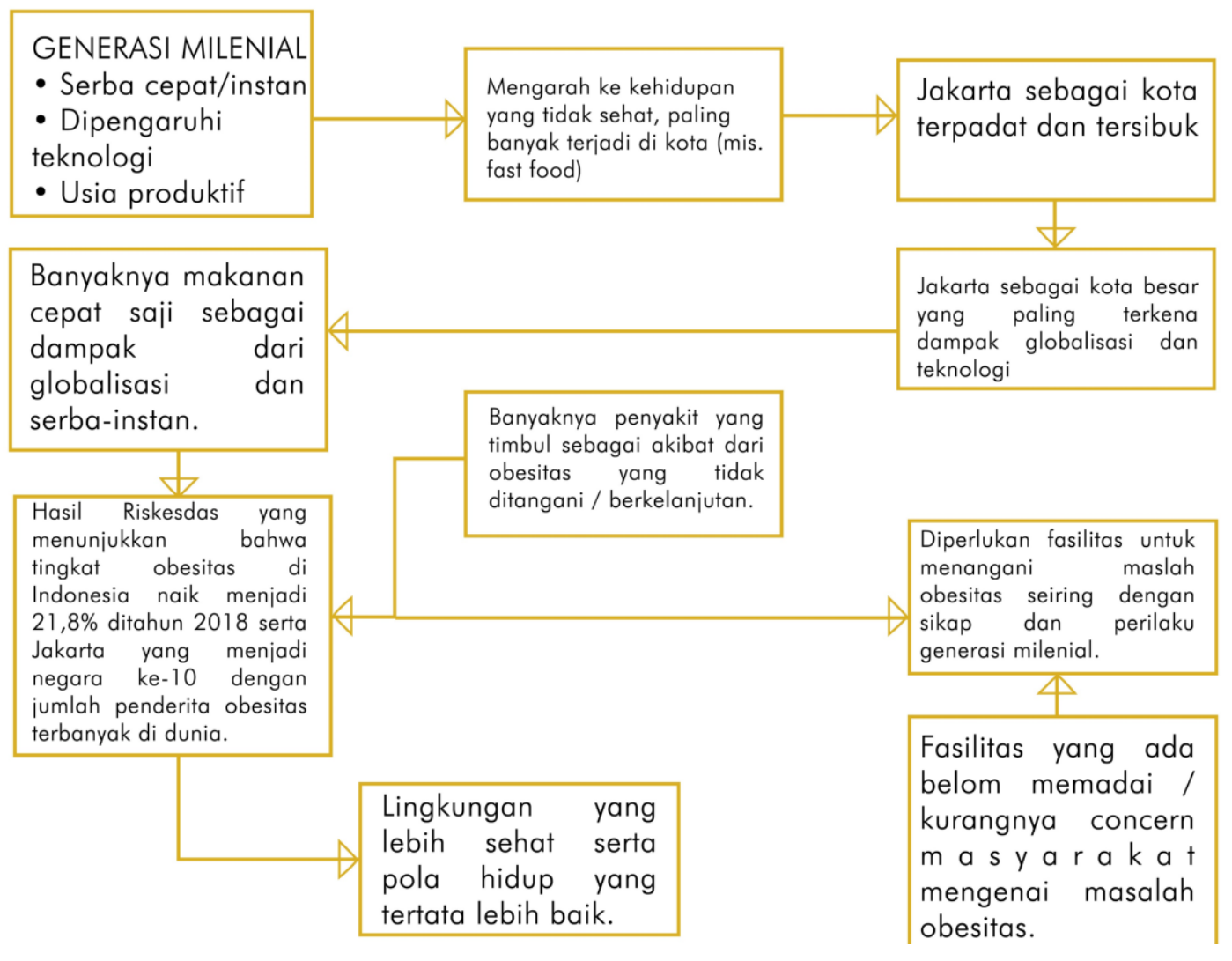

Gambar 2. Kerangka Pola Pikir Isu

Sumber: Penulis, 2019

\section{Studi Preseden}

Preseden dicari dengan mengumpulkan jenis-jenis proyek yang berkesinambungan dengan proyek seperti rumah pengobatan (treatment center) ataupun rumah sakit. Studi preseden berfungsi sebagai pembanding antar-proyek serta sebagai standar acuan untuk mendesain. 


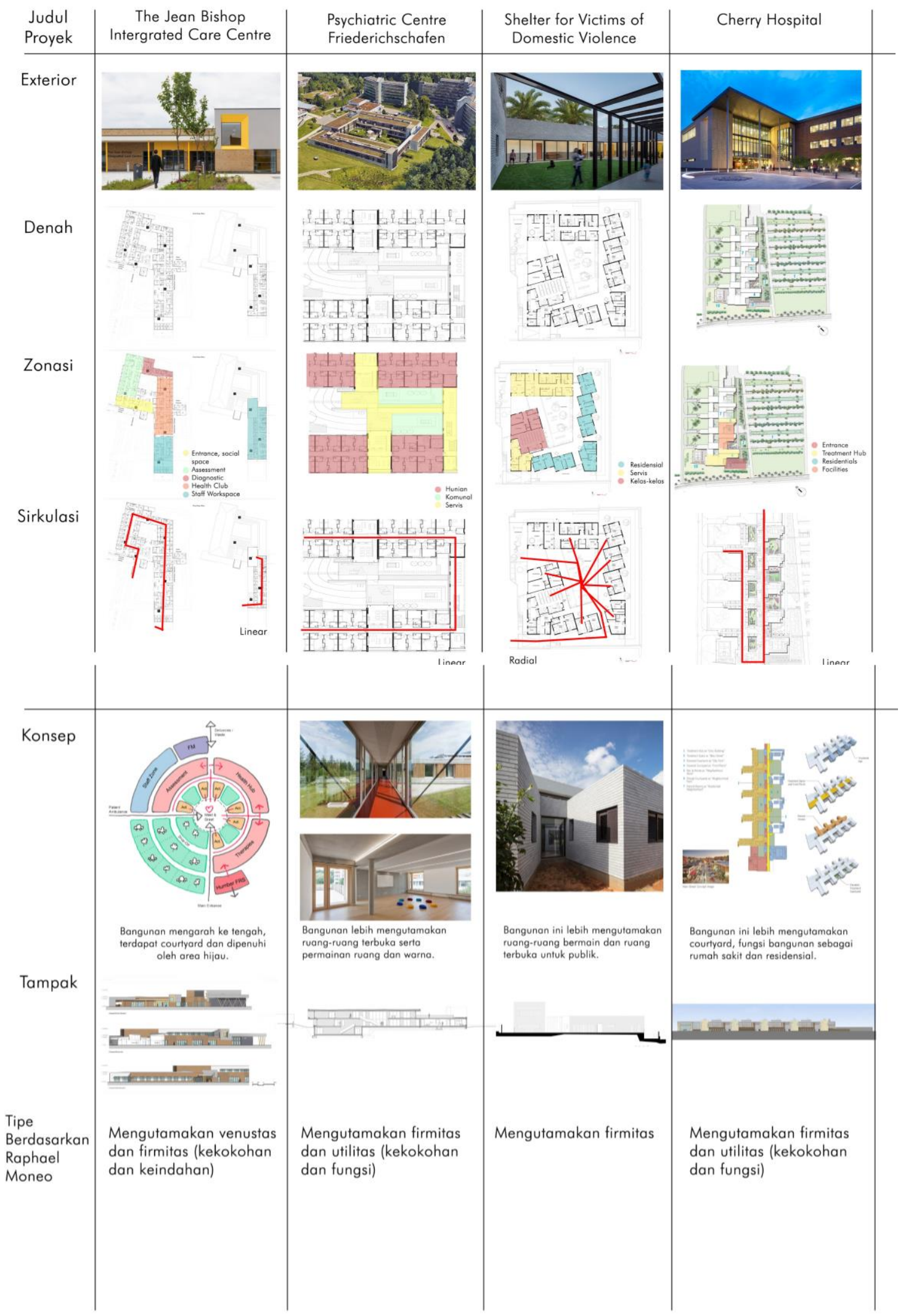

Gambar 3. Studi Preseden Rumah Sakit Sumber: Penulis, 2019 


\section{Studi Literatur}

Studi literatur juga dapat digunakan sebagai landasan teoritis untuk dasar konsep pemikiran, serta untuk mengetahui usulan-usulan program proyek yang akan ditawarkan. Studi literatur juga berguna untuk mengetahui standar yang berhubungan dengan batasan-batasan proyek.

Studi literatur yang dimaksud lebih berfokus kepada program yang akan dikembangkan ke dalam proyek. Literatur-literatur tersebut berupa kajian mengenai psikoterapi sebagai program utama, dan program-program fasilitas kesehatan yang telah ada seperti gym, spa serta fasilitasfasilitas penunjang untuk fasilitas publik. Literatur yang digunakan berasal dari buku The Psychology Book: Big Ideas Simply Explained dengan berbagai topik bahasan mengenai psikoterapi dari psikolog-psikolog, mengenai bagaimana sikap lingkungan sosial terhadap perilaku seseorang kedepannya.

\section{DISKUSI DAN HASIL}

Berdasarkan studi preseden yang telah diambil, ditemukan sebuah konklusi mengenai bentuk arsitektur rumah sakit / fasilitas rehabilitasi, yaitu:

- Fasilitas kesehatan umumnya berorientasi kepada pasien

- Memiliki sirkulasi linear

- Memiliki area hijau yang cukup dan memadai

- Memiliki tempat berkumpul terpusat seperti courtyard

\section{Analisa dan Sintesa Lingkungan}

Tapak berada di kawasan Pantai Indah Kapuk, Jakarta Utara. Kawasan tersebut merupakan salah satu dari kawasan pusat kuliner di Jakarta dimana intensitas orang-orang yang datang setiap harinya semakin bertambah. Selain merupakan pusat kuliner, di daerah tersebut juga dekat dengan sekolah, perkantoran dan perumahan penduduk sehingga tapak memiliki potensi user yang beragam.

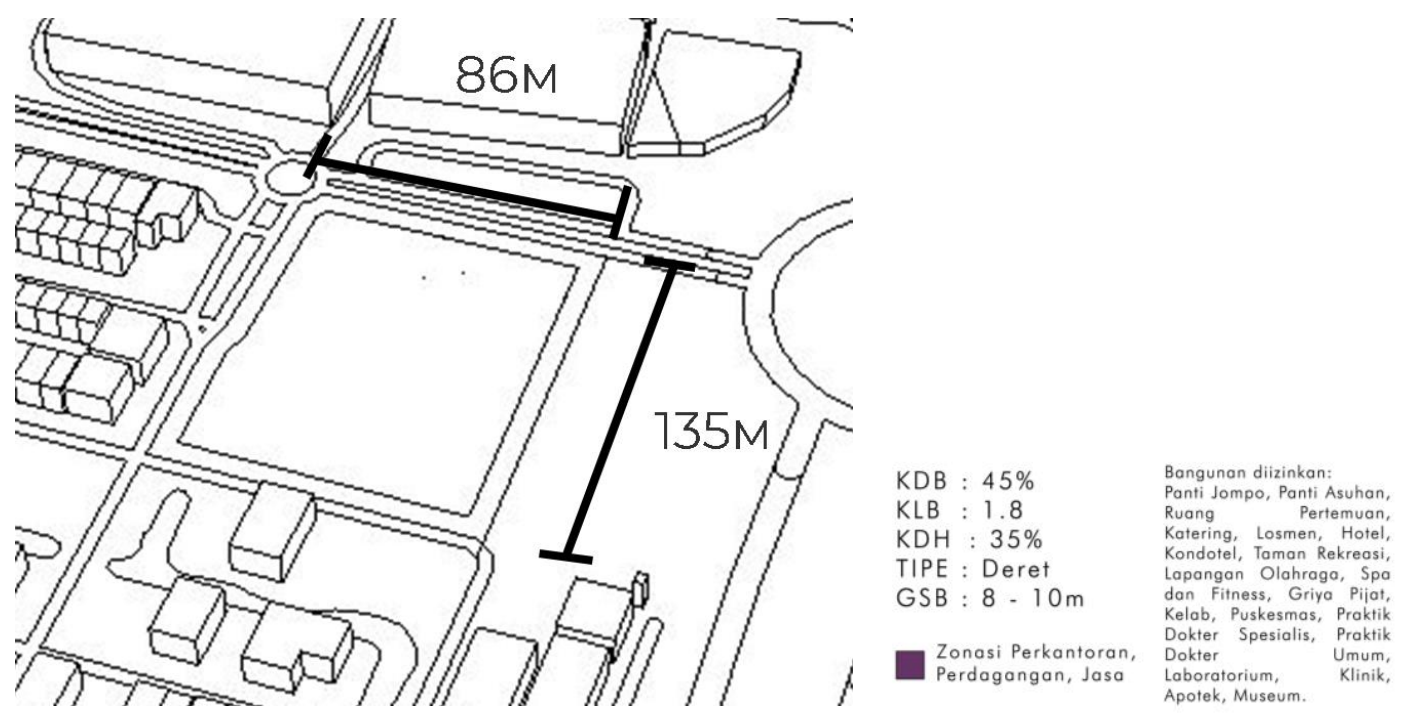

Gambar 4. Ukuran dan Data Tapak

Sumber: Penulis, 2019 


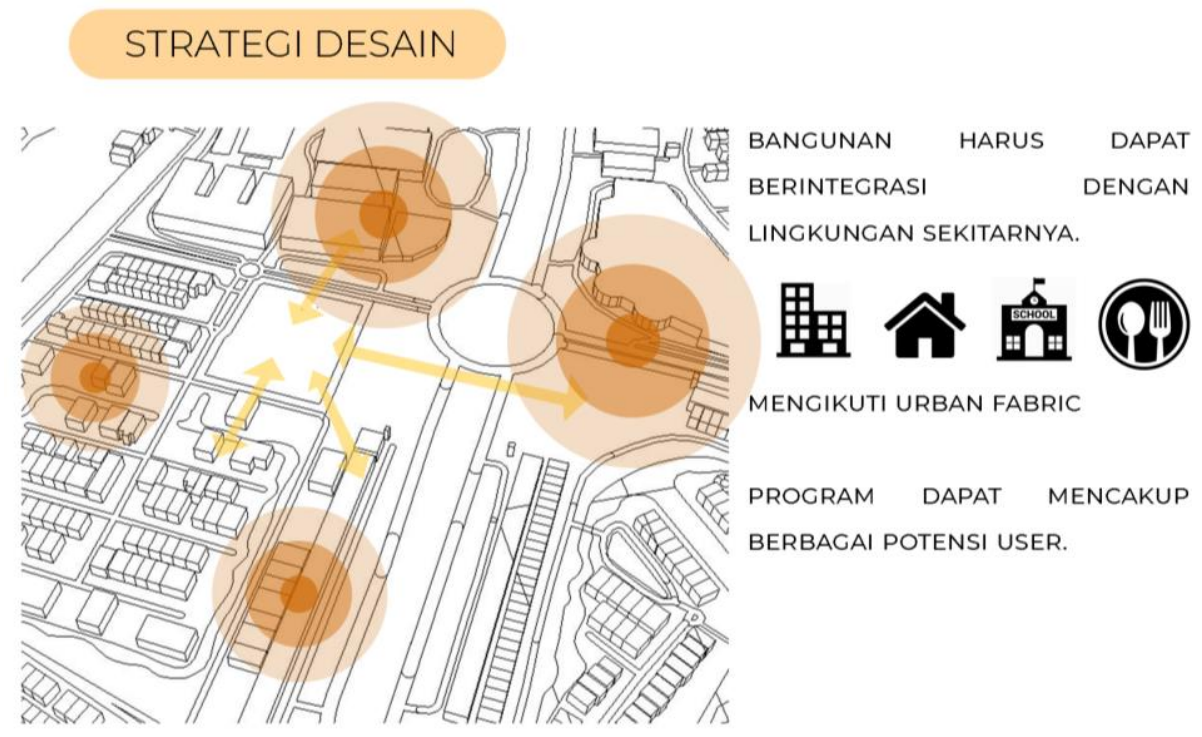

Gambar 5. Strategi Desain

Sumber: Penulis, 2019

\section{Gubahan Massa dan Konsep Bangunan}

Gubahan massa bangunan diambil dari bentuk-bentuk lemak pada tubuh manusia yang mengalami obesitas kemudian dikumpulkan dan ditumpuk menjadi sebuah kolase sehingga terbentuk garis luar sebagai dasar bentukan massa. Sedangkan konsep bangunan ini sendiri diambil dari 5 tipe kepribadian menurut Lewis Goldberg yang kemudian diterjemahkan sebagai bentuk-bentuk ruang.
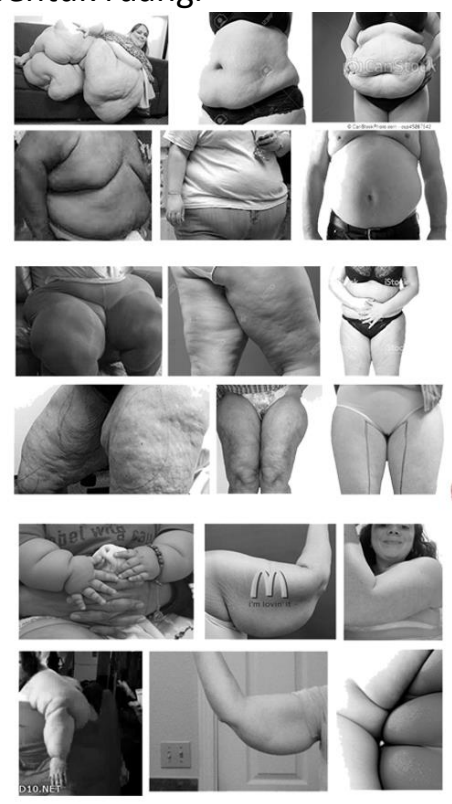
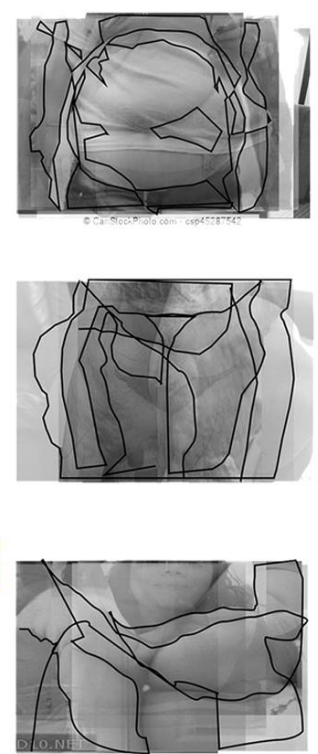

\section{DESIGN SCHEME}
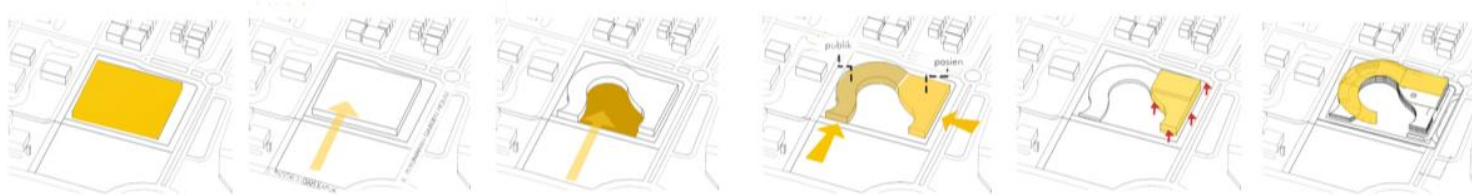

Gambar 6. Gubahan Massa

Sumber: Penulis, 2019 


\section{Program}

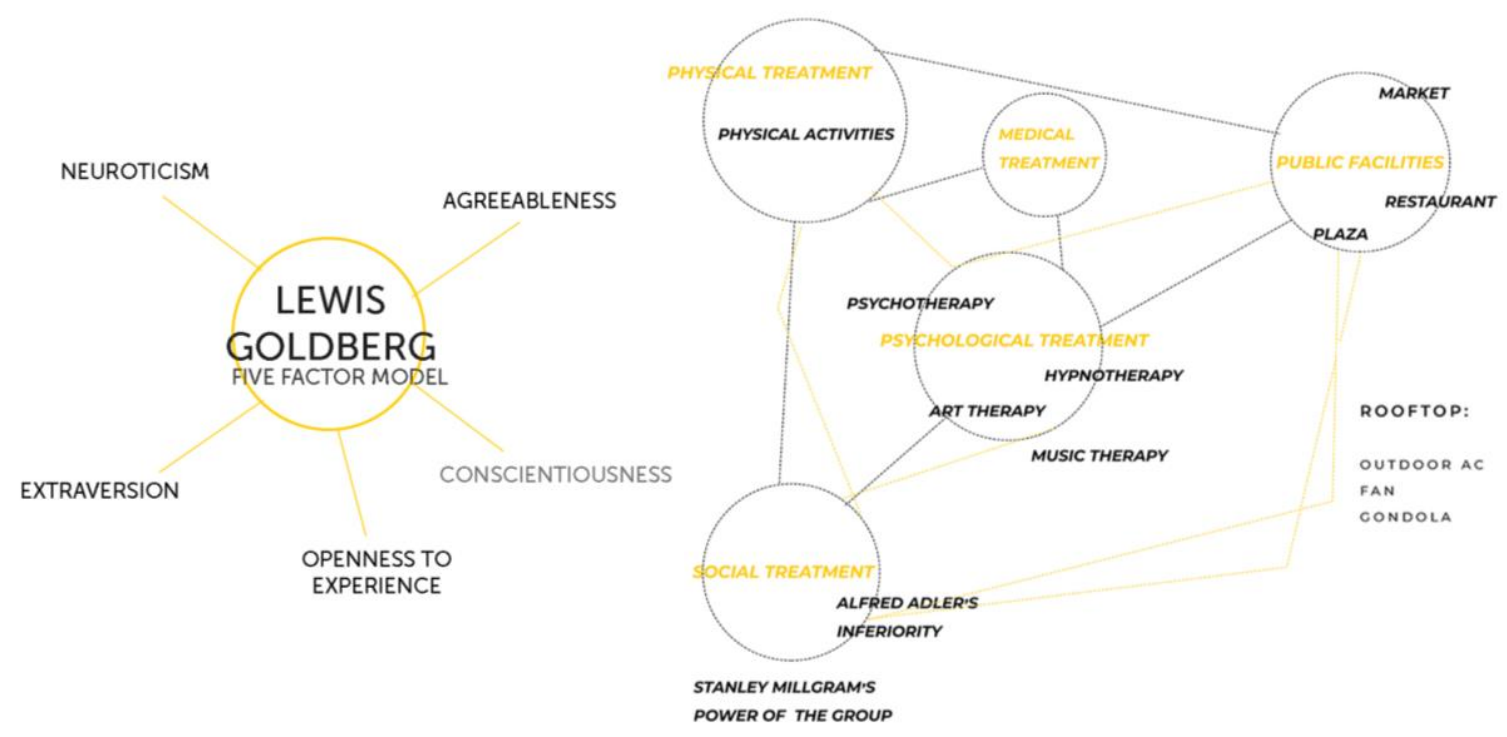

Gambar 7. Diagram Konsep

Sumber: Penulis, 2019

Sedangkan untuk program bangunan dapat diurai berdasarkan lima kepribadian dasar manusia yang masing-masing dapat dijadikan landasan acuan untuk pengobatan bagi penderita obesitas. Lima kepribadian tersebut hanya merupakan kepribadian yang berhubungan langsung dengan berat tubuh manusia, yaitu neurotisisme, keterbukaan, ekstraversi dan mudah menerima segala sesuatu. Setelah menyesuaikan ruang-ruang dengan kebutuhan, setiap ruang disusun berdasarkan zonasi dimana bagian-bagian yang satu zonasi diletakkan secara berdekatan dengan akses secara langsung. Terdapat 3 jenis ruang utama sebagai ruangan untuk terapi yakni terapi psikologis, terapi fisik dan medis.

Peran publik juga cukup penting bagi masa terapi penderita obesitas. Hal ini diangkat berdasarkan teori psikoterapi sosial dimana publik mengambil peranan penting dalam memberikan persepsi seseorang terhadap bentuk tubuhnya, sehingga peran publik dapat dimasukkan menjadi salah satu program terapi dimana pasien obesitas dapat merefleksikan dirinya melalui apa yang ia lihat dari lingkungan di sekitarnya.

Jalur sirkulasi pasien dan pengunjung dipisahkan selain untuk kenyamanan pasien, tetapi juga agar terjadinya sebuah pertemuan di bagian courtyard. Pertemuan atau interaksi antara pasien dengan pengunjung publik dimaksudkan sebagai salah satu bentuk terapi sosial. Tetapi, sebelum pasien dapat memasuki ruang terapi sosial, pasien terlebih dahulu harus melakukan registrasi di bagian lobi dan melakukan pemeriksaan fisik serta psikologis. Sosial terapi bersifat opsional, dimana pasien boleh memilih untuk melakukannya atau tidak.

Pemeriksaan fisik merupakan salah satu pemeriksaan wajib yang harus dilakukan oleh pasien dimana pasien akan mengetahui separah apa obesitas yang sedang dihadapinya, dan pemeriksaan bagi pasien yang mengalami obesitas akibat kelainan genetik. Dari pemeriksaan fisik, kemudian pasien akan melakukan fase pengecekan secara psikologis untuk pasien yang mengalami obesitas tanpa riwayat keluarga obesitas, dan pasien yang mengalami obesitas akibat pola perilaku sebagai dampak psikologis.

Setelah melalui rangkaian pengecekan secara psikologis dan fisik, jika pasien tersebut didiagnosa menderita obesitas akibat genetik, dan dalam artian kondisi psikologis pasien menurut 5 tipe kepribadian normal, maka pasien dapat langsung melakukan terapi fisik dan terapi sosial dibawah pengawasan medis. Sedangkan, untuk pasien yang mengalami obesitas sebagai akibat dari kondisi perilaku, pasien akan terlebih dahulu diberikan pengobatan secara psikologis sesuai 
dengan kepribadian mana kondisi psikis pasien tersebut yang harus diprioritaskan. Tidak hanya pengobatan psikologis, tetapi pasien juga dirujuk untuk pengobatan fisik dan pengobatan sosial.

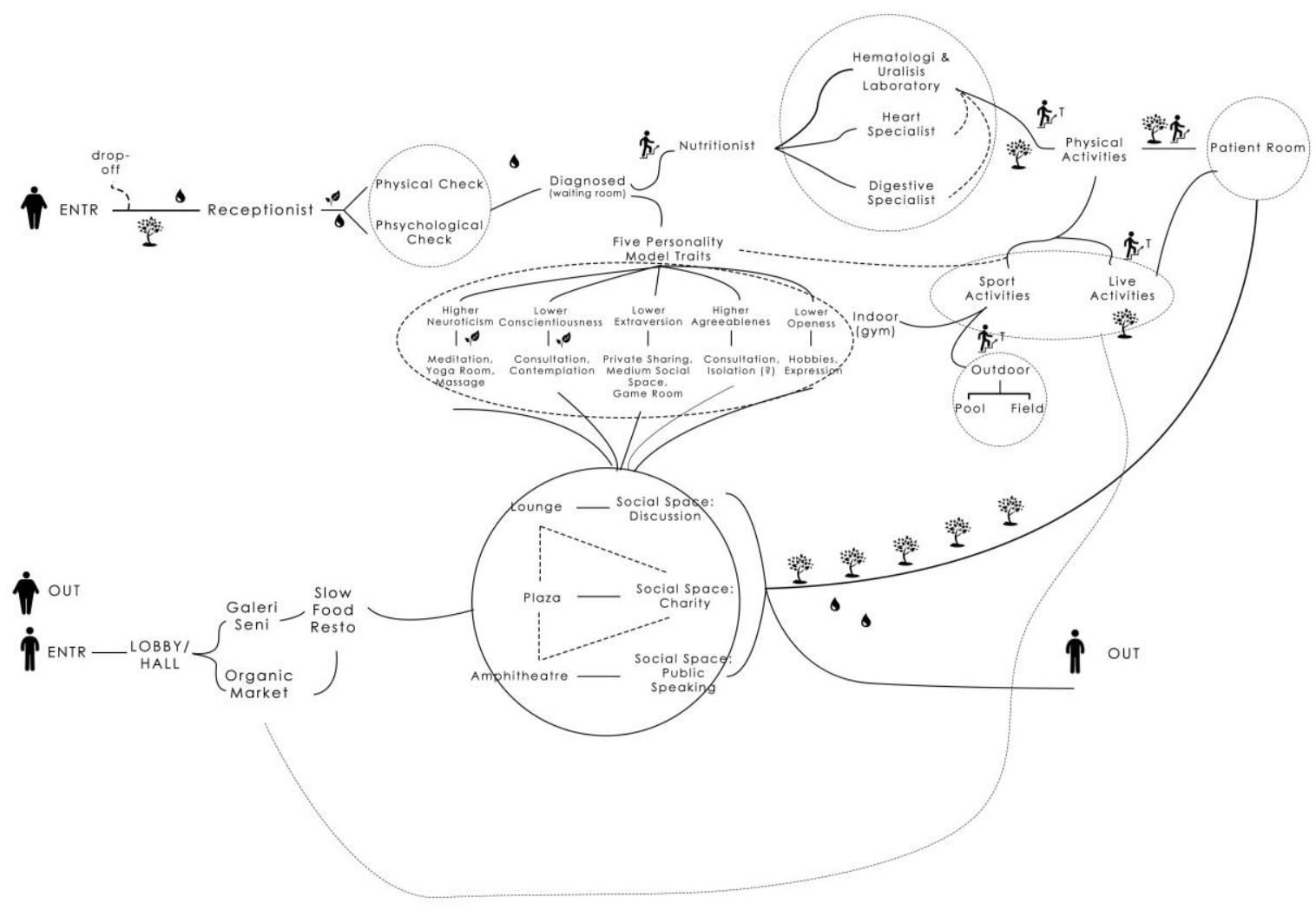

Gambar 8. Flow Program

Sumber: dokumentasi pribadi

\section{KESIMPULAN DAN SARAN}

Proyek ini tentu masih dapat dikembangkan lebih lanjut dengan menggunakan metode yang lebih beragam, teoritikal dan variatif. Hal itu tentu dapat mempengaruhi proses desain yang berlangsung setelahnya, agar produk arsitektur yang dihasilkan dapat menjadi lebih baik dan bermanfaat tidak hanya bagi pasien penderita obesitas, tetapi juga berdampak positif terhadap lingkungan di sekitarnya.

\section{REFERENSI}

Brummett BH, Babyak MA, Williams RB, Barefoot JC, Costa PT, Siegler IC. (2006). NEO personality domains and gender predict levels and trends in body mass index over 14 years during midlife. Journal of Research in Personality. 2006;40:222-236

Caballero, B (2007). The Global Epidemic of Obesity.

Chapman BP, Fiscella K, Duberstein P, Coletta M, Kawachi I. (2009). Can the influence of childhood socioeconomic status on men's and women's adult body mass be explained by adult socioeconomic status or personality? Findings from a national sample. Health Psychology. 2009;28:419-427.

Garner DM, Wooley SC (1991). Confronting the failure of behavioral and dietary treatment of obesity.

Goodwin RD, Friedman HS (2006). Health status and the five-factor personality traits in a nationally representative sample. Journal of Health Psychology. 2006;11:643-654. 
Haslam, D (2007). Obesity: a medical history.

Kakizaki M, Kuriyama S, Sato Y, Shimazu T, Matsuda-Ohmori K, Nakaya N, et al. (2008). Personality and body mass index: A cross-sectional analysis from the Miyagi Cohort Study. Journal of Psychosomatic Research. 2008;64:71-80.

National Institutes of Health (1992). Methods for voluntary weight loss and control

Raven M.D., Gerald M (2006). Syndrome X: a short history.

Sugondo, S., (2009). Obesitas. In: Sudoyo, A.W., Setiyohadi, B., Alwi, L., Simadibrata, M., Setiasti, S., editors. Buku IImu Penyakit Dalam Jilid 3. Jakarta: Departemen Ilmu Penyakit Dalam Fakultas Kedokteran Universitas Indonesia pp 1973.

Terracciano A, Sutin AR, McCrae RR, Deiana B, Ferrucci L, Schlessinger D, et al. (2009). Facets of personality linked to underweight and overweight. Psychosomatic Medicine. 2009;71:682689. 